\title{
Assessment of the ethanol withdrawal state in the rat by means of repeatedly elicited audiogenic seizures
}

\author{
MILTON A. TRAPOLD \\ Memphis State University, Memphis, Tennessee 38152 \\ and \\ HENRY L. SULLIVAN \\ University of Minnesota, Minneapolis, Minnesota 55455
}

\begin{abstract}
This study explored the feasibility of using the probability and strength of elicited audiogenic seizures for assessing the severity of the withdrawal state of alcohol-addicted rats at various points in alcohol withdrawal. Results indicate that both seizure probability and seizure strength vary systematically and appropriately with time in withdrawal, with duration of prior alcoholization, and with diazepam treatment, but they are independent of the number of prior seizure tests that have been administered to a particular subject.
\end{abstract}

It is well established that physiological dependence upon ethanol can occur in a number of animal species (cf. Hunter, Riley, Walker, \& Freund, 1975; Mello, 1973). Prolonged exposure to relatively high blood ethanol levels produces an organism that, when alcohol is removed from its system, exhibits a variety of behavioral and physiological symptoms, in a more or less predictable sequence, which collectively define the withdrawal or abstinence syndrome for that species. In the case of the laboratory rat, several investigators have conducted very careful observational studies of the withdrawal syndrome and have provided detailed descriptions of the more readily observed behavioral components of that syndrome (Hunter, Boast, Walker, \& Zornetzer, 1973; Hunter et al., 1975; Majchrowicz, 1975).

Included in the rat ethanol withdrawal syndrome are such reactions as piloerection, tail stiffening, elevation, arching, slow, clumsy gait, tremors and spasticity, insomnia, anorexia, adipsia, reduced grooming, motor hypoactivity, motor hyperactivity, extensor rigidity, and both spontaneous and elicited seizures.

One of the more serious problems confronting one who wishes to investigate the relationship among severity, time course, duration, and other dimensions of the withdrawal processes and possible controlling variables is the absence of simple, objective, and reliable measurement techniques for assessing the relative

This research was supported in part by a grant from the graduate school of the University of Minnesota and NICHHD Grant HD01136 to the Center for Research in Human Learning, University of Minnesota. Requests for reprints should be sent to Milton A. Trapold, Department of Psychology, Memphis State University, Memphis, Tennessee 38152. severity of the withdrawal reaction. To be maximally useful, such a technique should span only a brief period of time and should be applicable repeatedly to the same subject without serious distortion of any particular measurement by previous measurements (Goldstein, 1977)

On the basis of informal observations of rats in ethanol withdrawal which were subjected to auditory stimuli that sometimes elicit audiogenic seizures, we were prompted to explore the feasibility of using the frequency and/or severity of repeatedly elicited audiogenic seizures as a measure of the severity of the withdrawal state. This experiment is our initial attempt to do that.

\section{METHOD}

\section{Subjects}

Subjects were seven male Sprague-Dawley albino rats (Holtzman), approximately 13 months old at the beginning of the experiment. Two subjects died during the course of the experiment, so Tests 2 and 3 are based upon six subjects and Tests 4 and 5 on five subjects.

\section{Apparatus}

Except for occasional weighings and seizure testing (described below), each subject was housed for the entire experiment in an individual cage measuring $15 \times 25 \times 25 \mathrm{~cm}$ high and constructed so that a container of ground Purina Lab Chow could be automatically inserted into or removed from the animal's reach through a hole in the cage floor.

Seizure testing was conducted in a $45 \times 25 \times 15 \mathrm{~cm}$ high opaque plastic chamber, the lid of which was a latchable metal grid that permitted unobstructed vision of the subject and open transmission of the seizure-eliciting sound to the subject. The seizure-eliciting sound was produced by a ring of 12 brass keys suspended $12 \mathrm{~cm}$ above the top of the center of the test chamber on the end of a metal rod that was driven up and down 
by an electric motor through a vertical distance of $1.25 \mathrm{~cm}$, at the rate of 1,715 complete vertical displacement cycles per minute.

\section{Procedure}

During all alcoholization phases of this study, subjects remained in their living cages, in which ethanol in sweetened tap water was continuously available (as the only fluid) through a ball-tipped drinking tube. The food containers were presented to subjects for $5 \mathrm{sec}$ every $120 \mathrm{sec}$ during every 4 th hour, on a continuous basis. This procedure provided subjects with enough food to maintain their weights at approximately $80 \%$ of ad-lib weight.

Subjects were maintained on this regimen continuously for 66 days prior to the first withdrawal test series. Across these days the percentage alcohol available to subjects as drinking fluid was varied according to the following schedule: $0 \%, 8$ days; $4 \%, 4$ days; $6 \%, 2$ days; $8 \%, 2$ days; $16 \%, 2$ days; $32 \%, 6$ days; $50 \%, 8$ days; $25 \%, 6$ days; $40 \%, 28$ days. All subsequent alcoholization was with $40 \%$ alcohol solution. During withdrawal tests the periodic delivery of food was continued, and tap water was continuously available.

On a seizure test, an individual subject was removed from the home cage, placed into the testing chamber, and carried to the acoustically isolated seizure testing room. The seizure test chamber was positioned beneath the key ring, and after a delay of approximately $20 \mathrm{sec}$, the automatic key jingler was energized until the subject either entered a seizure of Strength 2 or greater (see below) or $3 \mathrm{~min}$ had passed. After all signs of violent seizure activity had ceased, the subject was returned to its home cage.

The several withdrawal test series of this experiment are summarized in Table 1. Each test series was conducted during ethanol withdrawal following a period of alcoholization, the duration of which varied across test series, as specified in Table 1. In each test series, each subject was tested at several points in withdrawal, again as specified in Table 1 . The alcoholization period for the next test series began immediately following the last seizure test of a given test series.

Between the 3- and 6-h tests $(4.5 \mathrm{~h})$ of the fifth test series, all subjects were administered a single interperitoneal injection of $5 \mathrm{mg} / \mathrm{kg}$ diazepam.

\section{RESULTS AND DISCUSSION}

Mean daily ethanol consumption in blocks of 5 days preceding each withdrawal is presented in Table 1.

In general, ethanol consumption was in a range that has previously been shown to be effective in producing dependence (Mello, 1973). Moreover, consumptions generally increased over the course of the experiment.

The audiogenic seizure pattern that we observed was very dramatic and corresponded closely to previous published descriptions (Falk, Samson, \& Winger,
1972; Hunter et al., 1975). In general, application of the key-jingling stimulus produced an increase in general locomotor activity (primarily moving about the test chamber and sniffing at the metal grid top) regardless of whether a seizure was forthcoming or not. When a seizure did not occur, this increase in activity usually persisted throughout the 3-min testing period. When a seizure did occur, this increased activity would abruptly change into a "rapid running" pattern consisting of staccato bursts of very fast frantic running about the chamber and clawing at the chamber top. Sometimes this rapid running was the extent of the seizure. Other times, however, rapid running gave way to a whole body tonic/clonic seizure that would last anywhere from a few seconds to several minutes. The most intenise portion of these seizures was often followed by one or more part-body (e.g., hind legs only, one side only, masticatory muscles, etc.) convulsive episodes (see also Hunter et al., 1973) prior to the onset of a period of postseizure flaccid immobility.

The latency of rapid running and other seizure activity was highly variable, but it generally ranged between 10 and $60 \mathrm{sec}$, with shorter latencies tending to characterize the stronger seizure episodes. We experienced considerable difficulty in developing objective criteria for deciding both the onset and the offset of seizure activity, and hence we will not comment further on the temporal characteristics of seizures.

We did, however, develop a quite reliable, although somewhat subjective scale for rating the severity of a seizure episode. No seizure was scored 0 , rapid running only was scored 1, a mild to moderate clonic/tonic seizure was scored 2, a severe clonic/tonic seizure, 3, and a seizure terminating in death, 4 . We never had to assign a score of 4 . Deciding between a score of 2 and 3 was the most difficult part of this scheme, because the assigned score depended upon both the duration and peak intensity of the seizure activity, and hence it did not convert neatly into any objective scoring rules that we could identify. Nevertheless, throughout the course of this study, we conducted independent ratings by two different raters on 60 separate seizure tests and found only one instance of disagreement between the two raters (a 3/2 disagreement).

Panels A and B of Figure 1 plot the results of withdrawal Test Series 1.4 in terms of the percentage of subjects showing any kind of seizure (score 1 or greater)

Table 1

Alcoholization Duration (Days), Alcohol Consumption (Grams per Kilogram), and Seizure Test Points for the Five Withdrawal Tests

\begin{tabular}{ccccrr}
\hline $\begin{array}{c}\text { Test } \\
\text { Series }\end{array}$ & Duration & $\begin{array}{c}\text { Mean Daily Consumption } \\
\text { for 5-Day Blocks } \\
\text { Preceding Withdrawal }\end{array}$ & $\begin{array}{c}\text { Seizure Test Points in } \\
\text { Withdrawal (Hours) }\end{array}$ & Tests* & Seizures** \\
\hline 1 & 66 & $13.34,11.16,11.91$ & $0,3,6,12,24,36,48,72,96$ & 9 & 3.4 \\
2 & 5 & 11.39 & $0,3,6,12,24,36,48$ & 4.6 \\
3 & 15 & $11.95,17.17,17.92$ & $0,3,6,12,24,36,48,72,96$ & 8.1 & 29 \\
4 & 5 & 16.96 & $0,3,6,12,24,36,48$ & 38 \\
5 & 15 & $15.45,16.05,20.32$ & 0,3, diazepam, 6, 12, 18, 24, 36, 48 & 45 & 11.5 \\
\hline
\end{tabular}




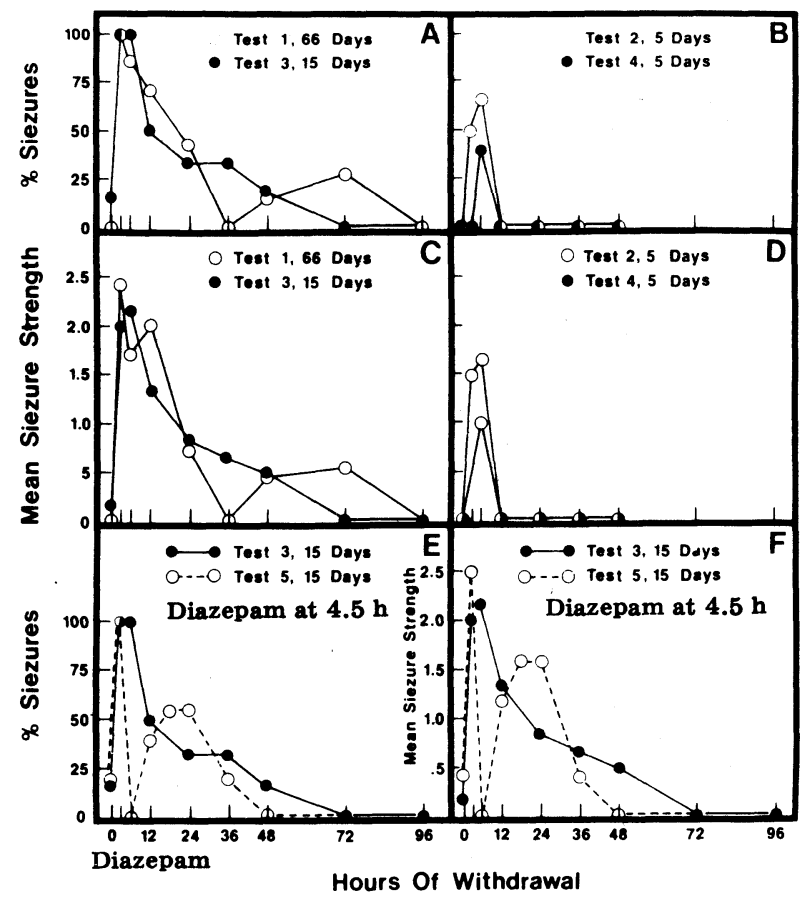

Figure 1. Percentage seizures and mean seizure strength for each of the five alcoholization withdrawal sequences. Frames $A$ and $C$ plot the results of Tests 1 and 3 on the same coordinates. Frames $B$ and $D$ do the same for Tests 2 and 4, and Frames $E$ and $F$ depict the seizure suppressing effect of diazepam.

on a test. Panels $C$ and D plot the same results in terms of the mean seizure strength score. Several points about these data are noteworthy.

First, even with the small number of subjects employed in this study, repeated seizure elicitations yielded very orderly functions having a shape and time course that is not surprising, given what is already known about alcohol withdrawal in the rat and in man (Goodman \& Gilman, 1975). Second, there were only minor differences between the 66-day and the 15-day tests, suggesting that 15 days of continuous alcoholization may produce near asymptotic addiction. Third, there were only minor differences between the two 5-day tests, suggesting that any particular seizure test is relatively free of distortion introduced by previous seizure tests on the same subject. Fourth, these data suggest that the time course of withdrawal is, at least within the limits employed here, independent of the total amount of alcoholization a subject has experienced in its lifetime; rather, it depends primarily upon the duration of continuous alcoholization immediately preceding the withdrawal experience (see also Goldstein, 1977). Fifth, seizure strength yielded essentially the same function as seizure probability and hence provided no additional benefits to offset the added element of subjectivity involved in obtaining that measure. Sixth, the greater probability and strength of seizures elicited during the first $6 \mathrm{~h}$ after the beginning of withdrawal is probably not due to the shorter time intervals employed between tests in this early part of withdrawal. A similar series of closely spaced tests inserted into the third test series between 72 and $78 \mathrm{~h}$ after the beginning of withdrawal did not increase seizures.

Finally, Panels E and F of Figure 1 provide additional evidence that the functions obtained across postwithdrawal times actually do reflect a process in rats similar to that involved in ethanol withdrawal in man. A common treatment for reducing the severity of withdrawal symptoms in man is the administration of one of the benzodiazepines. Panel E shows clearly that diazepam treatment in these rats blocked seizures on the ensuing 6-h test, but that this blocking had largely disappeared by the 12-h test.

In general, then, these data provide further evidence that the potentiation of audiogenic seizures is a component of the ethanol withdrawal syndrome in rats and that the likelihood and/or severity of such seizures varies in a very systematic fashion with the amount of time the subject has been withdrawn. Moreover, it appears that the method of seizure elicitation employed here provides a simple, objective, and reliable technique for taking repeated assays of the severity of the withdrawal state from the same subjects.

It should be noted that, in contrast with other reports of withdrawal seizures (e.g., Falk et al., 1972), we experienced no instances of seizure fatalities. Although we have not investigated this systematically, we suspect that our terminating the key-jingling stimulus as soon as subjects entered a clonic/tonic seizure was critical to this fact.

In summary, the results of this small investigation appear promising, and additional work to further establish the repeated seizure elicitation technique as a useful means of assessing alcohol addiction/withdrawal seems called for.

\section{REFERENCES}

Falk, J. L., Samson, H. H., \& Winger, G. Behavioral maintenance of high concentrations of blood ethanol and physical dependence in the rat. Science, 1972, 177, 811-813.

Goldstein, D. B. Characteristics of ethanol physical dependence. In T. Thompson \& K. R. Unna, (Eds.), Predicting dependence liability of stimulant and depressant drugs. Baltimore: University Park Press, 1977.

Goodman, L. S., \& Gilman, A. (Eds.). The pharmacological basis of therapeutics (5th ed.). New York: Macmillan, 1975.

Hunter, B. E., Boast, C. A., Walker, D. W., \& Zornetzer, S. F. Dissociation between physical dependence and volitional ethanol consumption: Role of multiple withdrawal episodes. Pharmacology, Biochemistry and Behavior, 1974, 2, 523-529.

Hunter, B. E., Riley, J. N., Walker, D. W., \& Freund, G. Ethanol dependence in the rat: A parametric analysis. Pharmacology, Biochemistry and Behavior, 1975, 3, 619-629.

MaJchrowicz, E. Induction of physical dependence upon ethanol and the associated behavioral changes in rats. Psychopharmacology, 1975, 43, 245-254.

Mello, N. K. A review of methods to induce alcohol addiction in animals. Pharmacology, Biochemistry and Behavior, 1973, 1, 89-101. 